\title{
Myelin Acquisition in the Central Nervous System of the Mouse Revealed by an MBP-Lac Z Transgene
}

\author{
David R. Foran and Alan C. Peterson \\ Department of Neurology and Neurosurgery, and Molecular Oncology, McGill University, Montreal, Quebec, \\ Canada H3A $1 \mathrm{~A} 1$
}

Myelin has pronounced effects upon the morphology, function, and growth of axons in the mammalian CNS. Consequently, oligodendrocyte development and myelination have been investigated using a wide variety of histological, immunocytochemical, ultrastructural, and biochemical techniques. While many of the spatial and temporal features of myelin appearance have been characterized, for any one species only limited regions of the CNS have been investigated. To address this limitation, we have derived transgenic mice in which the bacterial $\operatorname{Lac} Z$ gene is regulated by promoter elements of the myelin basic protein gene. When differentiating oligodendrocytes begin to elaborate recognizable myelin, they initiate expression of the MBP-Lac $Z$ transgene and accumulate readily detectable levels of $\beta$ galactosidase. Here, we exploit the sensitivity, resolution, and ease of $\beta$-galactosidase histochemical assays to characterize the temporal and spatial patterns of CNS myelination in the mouse. Many features of the myelination program revealed by this approach were predicted by the immunocytochemical and ultrastructural data derived from other species. Nonetheless, previously undocumented patterns were also encountered. $\beta$-Galactosidase was expressed first by oligodendrocytes in the ventral spinal cord, $1 \mathrm{~d}$ prior to birth. There, myelination proceeded in a strictly rostral-caudal direction, whereas in the dorsal cord, myelination initiated in the cervical enlargement and proceeded in both rostral and caudal directions. In the cerebellum, deep regions myelinated first, and in the optic nerve, myelination initiated at the retinal end. In contrast, the lateral olfactory tracts, pons, and optic chiasm initiated myelination along their entire course. The $\beta$-galactosidase marking system used here has several features that should complement the present methods by which myelinating oligodendrocytes can be identified in both in vivo and in vitro preparations.

\footnotetext{
Received Feb. 5, 1992; revised July 10, 1992; accepted July 14, 1992.

We gratefully acknowledge the assistance of S. Albrechtson, S. Gauthier, J. Tremblay, I. Tretjakoff, and P. Valera. We thank S. Vandaele for advice and A Beaudet, P. Foran, T. Owen, and W. Yong for helpful comments. D.R.F. is a postdoctoral fellow of the Ludwig Institute for Cancer Research. A.C.P. is an associate investigator of the Canadian Network for Neural Regeneration and Functional Recovery. This investigation was supported by the Montreal Branch of the Ludwig Institute for Cancer Research.

Correspondence should be addressed to Dr. Alan Peterson, Laboratory of Developmental Biology, Molecular Oncology, McGill University, Royal Victoria Hospital Research Institute, H-5, 687 Pine Avenue West, Montreal, Quebec, Canada H3A 1Al.

Copyright (C) 1992 Society for Neuroscience $0270-6474 / 92 / 124890-08 \$ 05.00 / 0$
}

A means of rapidly conducting action potentials over long distances is essential for normal nervous system activity. In vertebrates, this function is achieved by large-caliber axons that are invested with myelin, a structure elaborated by oligodendrocytes in the CNS and by Schwann cells in the PNS. As the acquisition of myelin signifies a major step in nervous system maturation, it has been investigated extensively by a wide array of techniques. As a result, the cellular processes and many of the molecules involved in myelin elaboration have been identified and extensively characterized.

Despite the fact that oligodendrocyte precursors can differentiate in vitro into cells that express many myelin-specific components (Zeller et al., 1985; Collins and Seeds, 1986; DuboisDalcq et al., 1986), various factors including those derived from neurons and astrocytes can exert a strong influence on this process (David et al., 1984; Shanker et al., 1987; Chen and DeVries, 1989; Giulian et al., 1991). Therefore, myelin elaboration in vivo is likely regulated by a number of diffusible and membraneassociated molecules present in the local environment of oligodendrocytes. In support of this view, myelin initiation is known to occur in different regions of the developing nervous system at widely different times. In an effort to characterize the major components contributing to this aspect of nervous system maturation, the temporal and spatial characteristics of oligodendrocyte differentiation have been investigated in several species using ultrastructural, immunocytochemical, and in situ methods (Vaughn, 1969; Knobler and Stempak, 1973; Skoff et al., 1976a,b; Tennekoon et al., 1977; Skoff et al., 1980; Dixon and Eng, 1984; Kristensson et al., 1986; Trapp et al., 1987). While such techniques can yield high-resolution preparations, they are difficult to apply to large regions of the nervous system and to appreciate in three dimensions. To circumvent these technical limitations, we have developed lines of transgenic mice bearing a fusion construct in which a modified $L a c Z$ reporter gene has been ligated to 3.2 kilobases $(\mathrm{kb})$ of the $5^{\prime}$ sequence flanking the mouse myelin basic protein $(M B P)$ gene. This construct encodes a partially attenuated SV40 large T nuclear localization signal sequence causing $\beta$-galactosidase to be distributed in both nuclear and cytoplasmic compartments (Kalderon et al., 1984).

Mice bearing this construct express $\beta$-galactosidase in oligodendrocytes at or near the time that MBP synthesis and myelin compaction occur, providing the basis of a sensitive in situ marker of myelination. The ease with which $\beta$-galactosidase activity can be detected in histochemical preparations provided an opportunity to track myelin acquisition throughout the developing CNS, and here we describe the major temporal and 
spatial patterns of transgene expression during the first 4 weeks ex utero.

\section{Materials and Methods}

Construction of MBP-Lac $\mathrm{Z}$ clones. The mouse $M B P$ clone pM2 was provided by A. Roach (Mount Sinai Hospital, Toronto). pM2 contains $3.2 \mathrm{~kb}$ of $M B P 5^{\prime}$ flanking sequence, with a Bsp MII restriction site that lies 12 base pairs upstream of the gene's start codon. pM2 was digested with Bsp MII and Xba I (which represent the $5^{\prime}$ most end of the clone) and inserted into the Xma I and Xba I sites of Bluescript $\mathrm{SK}^{-}$, respectively.

Modified Escherichia coli Lac Z genes were obtained from B. Roberts. The genes L7 and d10 contain a short stretch of SV40 large T-antigen signal sequence that targets $\beta$-galactosidase to the cell nucleus or nucleus and cytoplasm, respectively (Kalderon et al., 1984). These were digested with Bam HI, followed by a partial ( $2 \mathrm{~min}$ ) digestion with Hind III. The larger (complete) Hind III/Bam HI insert was cloned into the Hind III and Bam HI sites of Bluescript SK- ${ }^{-}$. This clone was digested with $X$ ba $I$ and Sal I, and the insert was ligated into the same sites of $\mathrm{pUC}$ 18. The pUC clone was digested with Sal I and $\mathrm{Kpn} \mathrm{I}$, releasing the $L a c$ $Z$ insert that was ligated into the same sites, immediately downstream of the $M B P$ promoter in Bluescript SK ${ }^{-}$described above.

Preparation of transgenic mice. For injection into zygotes, MBP-Lac $Z$ clones were digested with Not I and Kpn I, and the inserts were purified from low-melting-point agarose. Transgenic mice were generated by microinjection of this fragment into the male pronucleus of B6C3F2 zygotes. Positive mice were identified by PCR analysis of genomic DNA isolated from tail biopsies, using primers specific to the Lac $Z$ gene. Copy number estimates were made from Southern blots of genomic DNA.

Detection of $\beta$-galactosidase activity. Mice were anesthetized with avertin intraperitoneally and perfused transcardially with $0.5 \%$ paraformaldehyde, $2.5 \%$ glutaraldehyde in $0.1 \mathrm{~m}$ phosphate buffer ( $\mathrm{pH} 7.4$ ). Spinal cord, optic nerves, and brain were recovered and postfixed for an additional $45 \mathrm{~min}$. In older mice, the brain was cut into $1 \mathrm{~mm}$ sections using a rodent brain matrix. The samples were rinsed in $0.1 \mathrm{M}$ phosphate buffer and incubated overnight at $37^{\circ} \mathrm{C}$ in the same buffer containing $3.1 \mathrm{~mm}$ potassium ferricyanide, $3.1 \mathrm{~mm}$ potassium ferrocyanide, $1 \mathrm{~mm}$ $\mathrm{MgCl}_{2}$, and $0.4 \mathrm{mg} / \mathrm{ml}$ Bluo-gal (Bethesda Research Laboratories).

Microscopy. After staining for $\beta$-galactosidase activity, samples were viewed and photographed using a Leitz M5A microscope. Labeled spinal cords were also frozen, and $12 \mu \mathrm{m}$ cryostat cross sections were examined by light microscopy and labeled cells counted. Spinal cords from day of birth samples were postfixed in $2 \%$ osmium tetroxide $\left(4^{\circ} \mathrm{C}\right)$ in $0.1 \mathrm{M}$ phosphate buffer for an additional $24 \mathrm{hr}$. The tissues were then trimmed and embedded in Epon and sections for light and electron microscopy were prepared with a Reichert Jung Ultracut microtome. Samples were viewed and photographed with either a Zeiss Axiophot photomicroscope or a Phillips CM-10 Electron Microscope.

\section{Results}

Generation of transgenic mice

One hundred and sixty-six potential founder mice were derived: 86 from zygotes injected with an $M B P$ - Lac Z construct encoding an intact nuclear localization signal (L7 lines) and 80 from zygotes injected with a construct encoding an attenuated version of the nuclear localization signal (d10 lines). From these, $10 \mathrm{~L} 7$ and $7 \mathrm{~d} 10$-bearing mice were identified. In two of the d 10 lines, designated $\mathrm{d} 10-1$ and $\mathrm{d} 10-80$, in which the transgene loci contained low numbers (one to four) of construct copies, all oligodendrocytes appeared to express $\beta$-galactosidase at high levels during active myelinogenesis. Four further lines were found to express $\beta$-galactosidase in unexpected patterns. In two, $\beta$-galactosidase activity was detected only in a small number of oligodendrocytes, while in the other two, it was expressed only in ectopic sites. Mice from both the $\mathrm{d} 10-1$ and $\mathrm{d} 10-80$ lines were examined at 1,2, and 4 weeks of age, and at several older ages. No differences between their expression patterns were noted, and for this developmental study, homozygotes from the d1080 line were analyzed.

\section{Transgene expression and the initiation of myelination}

To determine the stage of oligodendrocyte maturation at which $\beta$-galactosidase was first expressed, spinal cord samples from neonatal transgenic mice were examined by electron microscopy. On the day of birth, the ventral spinal cord contained labeled cells in the most rostral portion. Spinal cord samples obtained both from this region and from more caudal, unstained segments were processed for electron microscopy. Caudal samples revealed neither compact myelin nor reaction product (results not shown). In contrast, sections from the rostral cord contained numerous profiles of large-caliber axons ensheathed with compacting myelin, and the oligodendrocyte cell bodies associated with such profiles were invariably labeled (Fig. 1). While the $\beta$-galactosidase expressed within these cells should be distributed in both the nuclear and cytoplasmic compartments, the reaction product is associated primarily with nuclear and plasma membranes. No reaction product was found in cells that were not also elaborating compact myelin. As MBP is required for the compaction of CNS myelin, these results demonstrate that readily detectable $\beta$-galactosidase activity was expressed by oligodendrocytes at or very near the time that they expressed the endogenous $M B P$ gene (Sternberger et al., 1978).

\section{Development of $\beta$-galactosidase-positive oligodendrocyte populations}

On the basis of the above results, we undertook a developmental study with the objective of determining the major spatial and temporal patterns of myelin initiation throughout the CNS. The substrate used in the $\beta$-galactosidase histochemical assay penetrates fixed tissues to a moderate extent, leading to successful cell labeling several hundred micrometers from the tissue surface. Therefore, to reveal the labeling patterns associated with superficial tracts, whole-mounts of the CNS were stained and examined either directly or after subsequent cryostat sectioning. To reveal the $\beta$-galactosidase-positive cells in the more internal tracts, 1-mm-thick, matrix-guided, razor blade sections were prepared and incubated as floating sections.

\section{CNS surface: spinal cord}

$\beta$-Galactosidase activity was detected first in scattered, faintly labeled cells on the ventral aspect of the cervical spinal cord of day 17 fetuses. One day later, on the day of birth, the dorsal aspect of the spinal cord also contained a small number of labeled cells sequestered adjacent to the mid-line at the level of the cervical enlargement (Fig. 2, panel 1). In contrast, the ventral cord had labeled cells distributed more uniformly across its entire width, extending caudally from its junction with the medulla oblongata to the upper thoracic level (Fig. 2, panel 2).

One day after birth (P. 1), the dorsal aspect of the cord contained labeled cells extending over the rostral three-quarters of the cord (total length, $21 \mathrm{~mm}$ ). In the rostral half, labeled cells formed a continuous line tightly sequestered in a narrow band adjacent to either side of the medial sulcus, while farther caudally they were scattered. In the ventral cord, an increase in both the number of labeled cells and their intensity of staining was observed. Labeled cells extended, in a relatively homogeneous pattern, over the rostral one-half of the cord. In the next one-quarter of the ventral cord, only scattered cells were observed, while in more caudal regions, no labeled cells were detected.

During the next $2 \mathrm{~d}$, labeled cells on the dorsal cord extended 

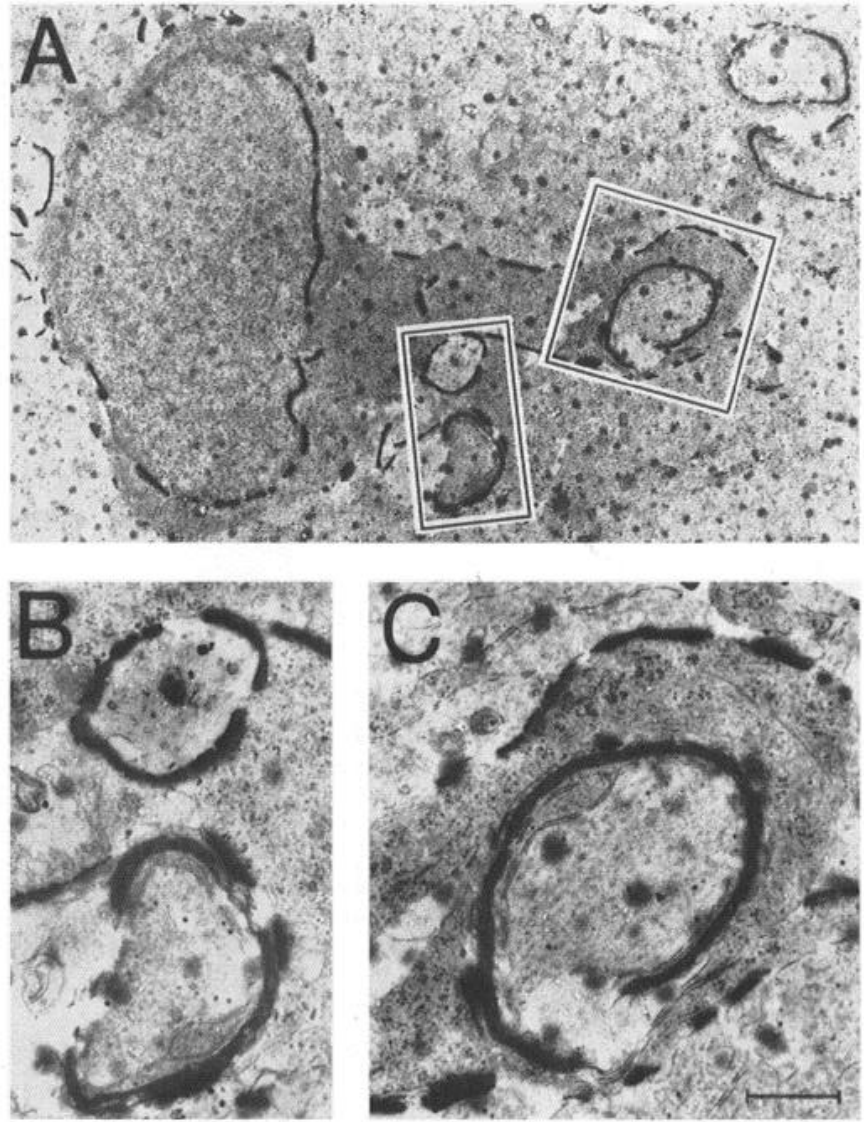

Figure 1. Ultrastructural appearance of $\beta$-galactosidase reaction product in a spinal cord oligodendrocyte on the day of birth. A, Low-magnification profile demonstrating reaction product deposited along nuclear and cytoplasmic membranes. $B$ and $C$, Higher magnifications revealing compacting myelin around the three ensheathed axons and further reaction product deposited along the outside of the myelin. Scale bar: $0.2 \mu \mathrm{m}$ for $A ; 0.07 \mu \mathrm{m}$ for $B$ and $C$.

into the medulla oblongata following the sulcus limitans of the fourth ventricle, becoming continuous by P.3 (Fig. 2, panel 3). At the cervical enlargement, where labeled cells were first observed, a denser labeling pattern was apparent. Caudally, labeled cells were present at a uniform density until the lumbar enlargement was reached; there, an increase in density, comparable to that observed at the cervical enlargement, was found (Fig. 2, panel 4). The caudal-most quarter of the cord remained unlabeled. Ventrally, an increase in the number of labeled cells was apparent, with the more rostral portions uniformly labeled (Fig. 2 , panels 5 and 6 ).

Over the next $3 \mathrm{~d}$, the cord elongated to approximately 28 $\mathrm{mm}$. On its lateral surface, a boundary between the ventrolateral tracts and the more dorsal gray matter became sharply defined. On its dorsal surface, labeled cells appeared in the relatively late-myelinating central projections of dorsal root ganglia neu- rons. By P.7, junctions between dorsal spinal roots and their labeled extensions in the CNS were becoming defined, and by P.8, cells flanking the medial sulcus, from the rostral limit of the medulla oblongata through the lumbar enlargement, were intensely labeled (Fig. 2, panels 8 and 9). Labeled cells were present on the central projections of all dorsal roots. Ventrally, from the medulla oblongata through to the middle of the lumbar enlargement, labeling had increased to such intensity that individual cells could not be distinguished.

By P.11, the general pattern of subsequent spinal cord labeling was emerging. The junctions of dorsal roots with the cord were demarcated. In the cervical cord, the tracts of each root were clearly separated (Fig. 2, panel 11; see panel 26 for higher magnification), while over the lumbar enlargement they assumed a more continuous herringbone pattern (Fig. 2, panel 12). On the ventral surface, with the exception of the most caudal $5 \mathrm{~mm}$, the entire cord was uniformly labeled at a density that obscured details of individual cells (Fig. 2, panels 14 and 15). Sharp demarcations of labeled spinal cord and unlabeled ventral spinal roots were found immediately adjacent to the spinal cord surface. This pattern of spinal cord labeling became progressively sharper and was maintained through P.23. Tracts of P. 23 dorsal roots were intensely labeled and sharply defined (Fig. 2, panel 17), while tracts of lumbar dorsal roots formed a continuous sheet of labeled cells (Fig. 2, panel 18; see panel 27 for higher magnification).

\section{CNS surface: ventral medulla oblongata and pons}

On the day of birth, labeled cells were observed in the most rostral course of the trigeminal nerve tracts. Extension of labeling from the ventral spinal cord into the medial longitudinal fascicle of the medulla oblongata was also evident. Over the next $3 \mathrm{~d}$, the density of labeled cells in the trigeminal tracts progressively increased (Fig. 2, panel 5) and scattered cells associated with additional tracts emerged; for example, 15 labeled cells could be detected in the P. 3 trapezoid body. This theme continued with apparently all superficial tracts containing labeled cells by P.8 ( Fig. 2, panel 7). The density of labeling increased substantially by P.11 (Fig. 2, panel 13), and both the number of labeled cells and the intensity of staining appeared to peak during the fourth week (Fig. 2, panel 16).

\section{CNS surface: midbrain and forebrain}

Two further tracts, the lateral olfactory tracts and the optic chiasm, course on or near the surface of the brain and were obvious in the whole-mount preparations (Fig. 2, panels 7, 13, and 16). The lateral olfactory tracts and the optic chiasm remained completely unlabeled through P.6. However, $1 \mathrm{~d}$ later, positive cells were present in both tracts. In the optic chiasm, labeled cells were initially distributed, apparently randomly, along its full lateral extent and progressively increased through P.23. The lateral olfactory tracts displayed a similar pattern of labeling beginning with a few labeled cells scattered along their entire course on P.7. The number of labeled cells increased

Figure 2. Developmental appearance of $\beta$-galactosidase-positive oligodendrocytes throughout the CNS of $M B P$-Lac Z d10-80 mice, from birth through the peak of myelin elaboration. Panels $1-21$ display surface features of oligodendrocyte labeling, including dorsal $(D)$ and ventral $(V)$ views of day of birth (D.B.) spinal cords, P.3 brainstem and spinal cord, as well as representative photos of brains and regions of the spinal cord during active myelinogenesis. An adult (P.120) nervous system is also shown. Panel 22 displays the labeling gradient expressed by optic nerves of a P.7 mouse. Panels 23-25 show sagittal sections of developing cerebellum revealing an internal to external progression of myelination. Panels 26 and 27 show dorsal spinal cords with details of dorsal root tracts in the thoracic region and in the lumbar enlargement, respectively. Panel 28 is a representative $1 \mathrm{~mm}$ mid-sagittal section of a brain from a P.23 mouse, at the peak of myelination. 

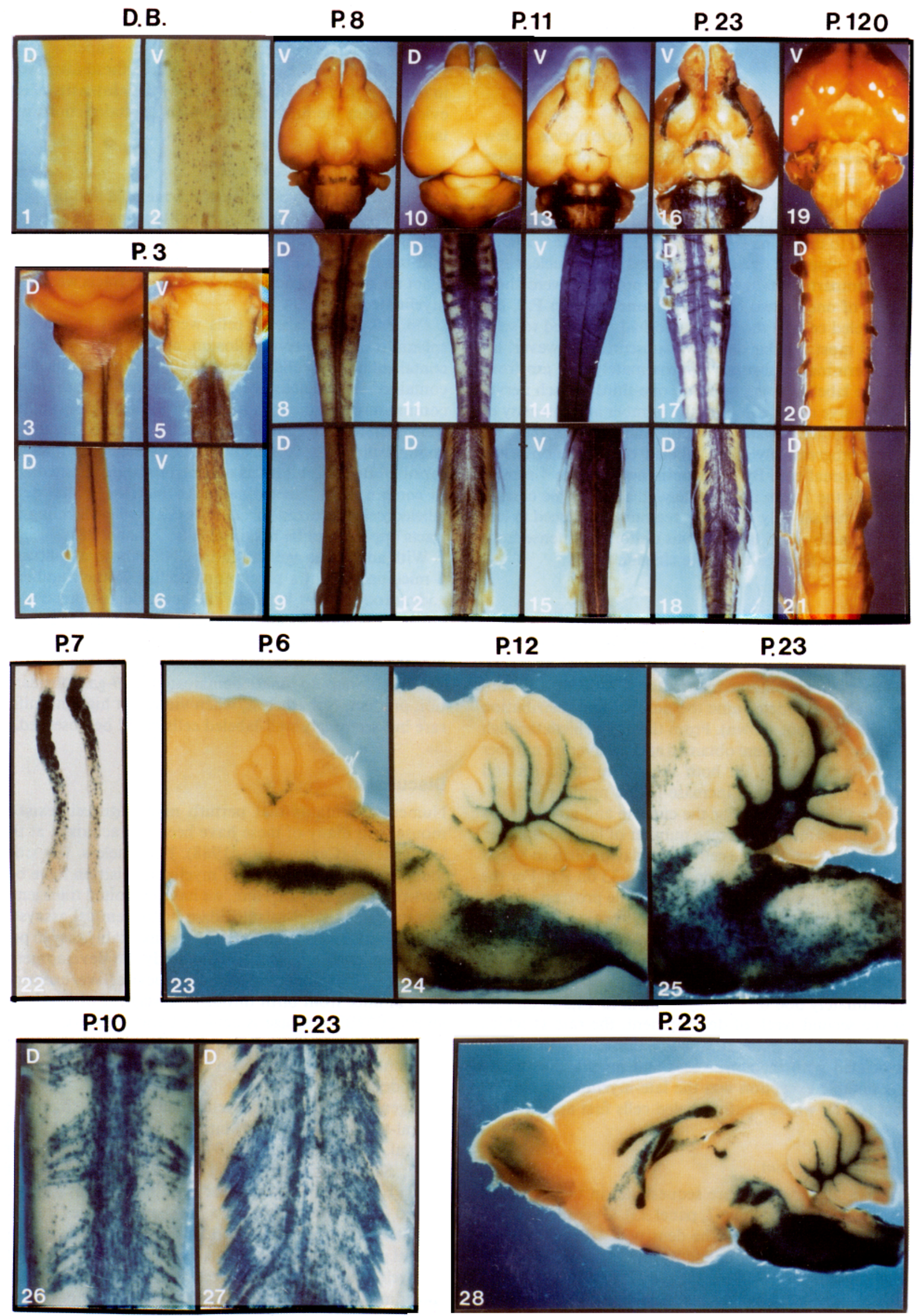
sharply through P.11, and, as for the optic chiasm, the intensity of label peaked during the fourth week ex utero.

\section{Optic nerves}

Prior to P.6, no labeled cells were found in optic nerves. A few labeled cells were detected in the optic nerves of one mouse analyzed late on P.6, while samples from a littermate that were prepared earlier in the day were negative. However, labeled cells were typically detected on P.7, concentrated in the region of the nerve proximal to the retina (Fig. 2, panel 22). Label associated with these cells appeared most concentrated in the nuclear and perinuclear compartments, while labeled processes were short (on the order of one or two cell body diameters). On P.8, the density of labeled cells in the retinal end had increased to such an extent that most cellular detail was obscured. However, labeling there terminated abruptly approximately $200 \mu \mathrm{m}$ from the eye. Dense labeling was present in one-third of each nerve, while a progressive decline in both the number and intensity of labeled cells occurred toward the optic chiasm. Over the next several days, progressively more labeled cells were observed toward the chiasmal end. By P.10, optic nerves were $4 \mathrm{~mm}$ in length and only the $1 \mathrm{~mm}$ immediately adjacent to the chiasm failed to label intensely. By P.11, this region was reduced to less than $0.5 \mathrm{~mm}$, and by P.15 labeling was uniformly intense from the lamina cribosa through the optic chiasm.

\section{Internal tracts: spinal cord}

After examining the spinal cord surface, the region containing the cervical enlargement was processed for cryostat sectioning. Sections $12 \mu \mathrm{m}$ thick obtained from the $\mathrm{C} 2-\mathrm{C} 3$ spinal cord level were analyzed to determine the number and distribution of labeled cells (data not shown). From the day of birth through P.6, at least four sections were obtained and the average number of labeled cells calculated. In both the dorsal funiculus and ventral lateral tracts, a linear increase in cell number was observed during the first week. For the cuneate and gracile tracts in the dorsal funiculus, the average number of labeled cells per section increased from a single cell on the day of birth to 8 cells on P.1, 13 on P.2, 19 on P.3, 29 on P.5, and 33 on P.6. For the ventral cord, a similar if slightly more variable progression was observed with an average of 5 labeled cells present on day of birth, 39 cells on P.1, 36 on P.2, 61 on P.3, 147 on P.5, and 141 on P.6. Extrapolating from these values, the number of myelinating cells within a $1 \mathrm{~mm}$ length of cervical cord rose from approximately 500 on the day of birth to 14,500 on P.6.

During the second week of development, the rate at which labcled cclls appcarcd modcratcd, but the intensity of the labeling associated with their processes and myelin sheaths increased. A notable exception was the late-myelinating cortical spinal tract (CST), where lightly labeled cells first appeared on P.11.

\section{Internal tracts: cerebellum}

On P.6, a few labeled cells were sequestered in the depths of the cerebellar hemispheres (Fig. 2, panel 23). Over the next few days, a pronounced increase in the density of labeled cells occurred in the caudal-most lobules. By P.10, the more dorsal lobules also contained labeled cells, and by P.12 all but the most rostral lobules were labeled (Fig. 2, panel 24). By P.23, uniform and intense labeling was observed throughout the cerebellum
(Fig. 2, panel 25). Intense label was also observed in a small number of fibers coursing laterally in the superior medullary velum (Fig. 2, panels 23 and 24). While these fibers were few in number, they were distinguished by their intensity of labeling, evident from the first stage at which sagittal sections were obtained (P.6).

\section{Internal tracts: extracerebellar}

On P.6, tracts coursing through the medulla and the pons contained labeled cells. By P.8, intense labeling was also observed throughout the tegmentum of the medulla oblongata, pons, and mid-brain extending into the diencephalon, indicating that most, if not all, of the ascending and descending tracts were becoming myelinated.

On P.9, a few labeled cells were present in the genu and splenium of the corpus callosum, and by P.10 the entire tract contained labeled cells. Also on P.10, the medial olfactory bulbs contained several heavily labeled cells, and in both the anterior commissure and the stria medullaries a few lightly stained cells were visible. On P.11, labeled cells appeared in the ventral commissure of the fornix and in the caudate-putamen (internal capsule). By P.12, all tracts destined to be myelinated appeared to contain some labeled cells. An increase in the density of labeled cells occurred through to P.23, when labeling in most tracts appeared to be maximal (Fig. 2, panel 28).

With advancing age, the entire CNS in both $\mathrm{d} 10-80$ and $\mathrm{d} 10$ 1 mice underwent a precipitous decline in the number of oligodendrocytes that labeled. The beginning of this decline was apparent in some locations as early as P.23-P.27, and the phenomenon was obvious in all regions of the CNS in mice 2 months of age or older. In the P.120 samples (Fig. 2, panels 1921 ), tracts were no longer demarcated by $\beta$-galactosidase reaction product. Nonetheless, when viewed at high magnification, rare but seemingly well-labeled cells could be observed.

\section{Discussion}

Numerous mutants that perturb myelinogenesis exist in the mouse, and many of these have been characterized at the molecular level (Campagnoni, 1988). Nonetheless, few studies of the normal sequence of CNS myelin acquisition have been reported for this species. Here, we have exploited transgenic mice and the facts that $\beta$-galactosidase histochemical assays can be carried out on well-fixed tissues, are remarkably easy to perform, and are exceedingly sensitive, to study the developmental appearance of myelinating oligodendrocytes. We examined the CNS of mice from birth through the stage at which the highest levels of MBP message is achieved and the maximum rate of myelination occurs, and therefore the present results can be compared to all previous investigations of myelinogenesis in the rodent CNS.

In general, spinal cord myelination is known to proceed in a rostral-to-caudal gradient (Matthews and Duncan, 1971; Knobler et al., 1974; Meier et al., 1974; Rozeik and Von Keyserlingk, 1987; Schwab and Schnell, 1989; Remahl and Hildebrand, $1990 \mathrm{a}, \mathrm{b})$. While the pattern of myelination that has been observed in the spinal cords of a number of species is quite consistent with the pattern we describe here, we have observed several previously unnoted features. These include: the initiation of myelination in the dorsal cervical enlargement followed by spreading in both the rostral and caudal directions; the higher labeling intensity transiently observed in the cervical and lum- 
bar enlargements relative to the intervening segment of the spinal cord; the medial-to-lateral gradient apparent on the tracts of the dorsal roots; and the long delay in myelination caudal to the lumbar enlargement (Fig. 2, panels 1-21, 26, and 27).

Neither myelin (Matthews and Duncan, 1971) nor MBP epitopes (Schwab and Schnell, 1989) are expressed in the CST of the rat spinal cord until the second ex utero week. In these transgenic mice, $\beta$-galactosidase was also expressed relatively late in the CST (P.11) whereas the adjacent cuneate and gracile tracts began to label on the day of birth. It will be of interest to determine if the late-labeling CST reveals any gradient of myelination and, if so, whether it displays a simple, unidirectional pattern or reiterates the bidirectional spreading pattern observed within the earlier-myelinating cuneate and gracile tracts.

In the optic nerves, a dramatic retinal-to-chiasmal gradient was obvious from the first appearance of labeled cells on P.6P.7 (Fig. 2, panel 22) through the second week of development. Both the origin of glia and the pattern of myelinogenesis in optic nerves have been investigated extensively in several species (Gyllensten and Malmfors, 1963; Gyllensten et al., 1966; Narang and Wisniewski, 1977; Perry et al., 1983; Sefton and Lam, 1984). In a detailed histological analysis of myelinogenesis in developing rat optic nerves, Skoff et al. (1980) also observed a general retinal-to-chiasmal gradient, albeit with many peaks and troughs encountered along the way including a specific delay at the optic foramen. In the mice examined here, a seemingly smooth progression toward the chiasm was typical and no delay at the level of the optic foramen was detected. This retinal-tochiasmal gradient contrasts with the apparent sequence of events thought to occur during earlier stages of glial differentiation (Skoff et al., 1976a,b). Specifically, in rat optic nerves, oligodendrocyte progenitor cells can be recovered initially from optic nerve segments at the chiasmal end and only as development proceeds from segments obtained closer to the retina. David et al. (1984) interpreted this observation to indicate that progenitor cells invade and populate the optic nerve from the chiasmal end. In light of this, the present observations require that the first cells to exit the oligodendrocyte progenitor pool and to initiate myelin synthesis be those that have migrated the farthest.

In optic nerves of mature rats, MBP immunocytochemical staining also has been observed in a narrow band on the retinal side of the lamina cribosa. Dixon and Eng (1984) concluded that such epitopes originated within oligodendroglial processes that had traversed the lamina cribosa. In the mice examined here, the majority of the $\beta$-galactosidase activity also stopped abruptly at the lamina cribosa but, at most ages examined, labeling was also observed in a narrow band on the retinal side. Despite the presence of these few positive processes, the consistent lack of $\beta$-galactosidase-positive nuclei in this more retinal course of the optic nerve clearly defines a domain in which myelinating oligodendrocytes either do not arise or fail to survive. This result is consistent with the suggestion that myelin encountered within the retina is elaborated by Schwann cells (Jung et al., 1978).

In the cerebellum, labeling initiates in the deepest regions and spreads toward the external surface (Fig. 2, panels 23-25) suggesting one of two myclin acquisition programs. Axons originating from Purkinje cells in the deepest regions of the cerebellum could become ensheathed and myelinated before any portion of those axons originating from cells located closer to the tips of the cerebellar lobules. Alternatively, axons originating from both deep and superficial Purkinje cells could become myelinated first in the deepest regions of the cerebellum.

The mice examined here, in addition to revealing the major temporal and spatial patterns of myelinogenesis, also provide evidence supporting the view that the length of the internodes maintained by oligodendrocytes varies inversely with the number of axons each ensheathes (Matthews and Duncan, 1971). For example, in tracts coursing in the spinal cord, long and continuously labeled processes are frequently seen originating from individual cell bodies (Fig. 2, panels 26 and 27). Assuming that the entire cytoplasm of these cells is labeled, few myelin sheaths are elaborated by each cell. In contrast, oligodendrocytes in the optic nerve (Fig. 2, panel 22) are distinguished by a labeling pattern in which much of the reaction product is located close to cell bodies, each of which appears to support a large number of short processes.

MBP expression in the mouse, and in particular the developmental regulation of the mouse $M B P$ gene, has been subject to extensive analyses (reviewed by Campagnoni, 1988). These investigations have revealed a complex pattern of alternate mRNA splicing that results in several size classes of MBP. In the brain, 21.5 and $17 \mathrm{kDa}$ isoforms dominate at early ages while 18.5 and $14 \mathrm{kDa}$ isoforms dominate in more mature mice (Carson et al., 1983). Differences in this pattern have been observed in the mouse spinal cord, leading Newman et al. (1987) to propose that the program of isoform switching may not be equivalent in all regions of the CNS. However, as seen here, in each region of the CNS labeled cells arise over a distinct and protracted period. Therefore, without in situ methods, the precise pattern and schedule of isoform switching that occurs within individual cells may be difficult to discern.

The promoter fragment included in the MBP-Lac Z construct appears to contain a significant portion of the elements used to confer developmental and cell-type specificity to the $M B P$ gene. Similar $M B P$ promoter elements have been used successfully to drive expression of the intact $M B P$ gene, its derivatives, or a variety of heterologous sequences in glial cells (Miura et al., 1989; Allinquant et al., 1991). In addition, the similarity of the expression pattern we observed in two independently derived lines of mice indicates that regulatory elements within the construct we employed act independently of further elements adjacent to the site of transgene insertion. Moreover, MBP synthesis in rodents peaks during the third week of ex utero development, thereafter declining to reach the lower steady state level observed in the mature nervous system (e.g., Zeller et al., 1984); the temporal features of this expression pattern are followed faithfully by $\mathrm{d} 10-1$ and $\mathrm{d} 10-80$ transgenic mice.

Despite all of the similarities observed between transgene and MBP expression, no $M B P$ promoter-driven construct convincingly follows the exact expression profile expected of the endogenous $M B P$ gene. The transgenic mice used in the present study did not show expression in Schwann cells, or in most oligodendrocytes of mature animals. In addition, in the present and all previous transgenic preparations, many oligodendrocytes in mature mice fail to express detectable levels of the transgene-encoded product, leading to a mosaic expression pattern. In those investigations that employed $M B P$ coding sequences themselves, analysis of transgenc expression on the MBP-deficient shiverer background resulted in a mosaic rescue of the hypomyelinated phenotype (Popko et al., 1987; Readhead et al., 1987) while an $M B P$-driven antisense construct caused a mosaic hypomyelinating disease in otherwise normal mice (Kat- 
suki et al., 1988). Similarly, mice bearing an $M B P-H-2 K$ construct displayed a mosaic pattern of demyelination (Turnley et al., 1991; Yoshioka et al., 1991).

All CNS myelin appears to contain abundant MBP, and therefore it seems highly improbable that the mosaicism expressed by transgenes also typifies the endogenous $M B P$ locus. We suggest that one of two mechanisms may account for this difference. The mosaic patterns expressed in the mature mice bearing these diverse constructs may identify unexpectedly large differences in the relative levels of MBP expression in stable oligodendrocyte subpopulations. In those cells that express low levels of MBP, the transgene encoded product may be expressed below detectable levels. Alternatively, as the promoter we have used drives transgene expression to detectable levels during active myelinogenesis, those few cells expressing the transgene in mature mice could also be those that are actively elaborating myelin or had recently done so. Consistent with the latter possibility, oligodendrocyte progenitors have been identified in the adult human CNS (Armstrong et al., 1992) and autoradiographic experiments have revealed a slow recruitment of new oligodendrocytes to the mature mouse brain (McCarthy and Leblond, 1988). In either case, the $3.2 \mathrm{~kb}$ sequence $5^{\prime}$ of $M B P$ exon 1 apparently does not contain the regulatory elements necessary to result in detectable $\beta$-galactosidase activity in the majority of fully mature oligodendrocytes present in the differentiated mouse CNS. It is formally possible that the construct used in the present experiment also fails to follow the exact MBP expression pattern that occurs during development. However, in comparisons between the present observations and all those derived from previous investigations of MBP developmental expression, no discrepancies have yet been encountered.

In this investigation, we have used expression of $\beta$-galactosidase in the d10-80 line of transgenic mice to obtain a comprehensive overview of oligodendrocyte maturation in different regions of the CNS. This marker should also be useful in further experiments, including those seeking to isolate the components involved in the regulation of the $M B P$ gene as well as those requiring an effective $i n$ situ marker of active myelinogenesis in both developing and regenerating preparations. Finally, the cytological detail preserved in $\beta$-galactosidase histochemical preparations may contribute to a greater appreciation of the full diversity of oligodendrocyte morphologies expressed in different CNS regions.

\section{References}

Allinquant B, Staugaitis SM, Urso DD, Colman DR (1991) The ectopic expression of myelin basic protein isoforms in shiverer oligodendrocytes: implications for myelinogenesis. J Cell Biol 113:393403.

Armstrong RC, Dorn HH, Kufta CV, Friedman E, Dubois-Dalcq ME (1992) Pre-oligodendrocytes from adult human CNS. J Neurosci 12: 1538-1547.

Campagnoni A (1988) Molecular biology of myelin proteins from the central nervous system. J Neurochem 51:1-14.

Carson JH, Nielson ML, Barbarese F. (1983) Developmental regulation of myelin basic protein expression in mouse brain. Dev Biol 96:485492.

Chen S-J, DeVries GH (1989) Mitogenic effect of axolemma-enriched fraction on cultured oligodendrocytes. J Neurochem 52:325-327.

Collins JM, Seeds NW (1986) Oligodendroglia development in cell culture as monitored with a monoclonal antibody. J Neurosci 6:26352643.

David S, Miller RH, Patel R, Raff MC (1984) Effects of neonatal transection on glial cell development in the rat optic nerve: evidence that the oligodendrocyle-type 2 astrocyte cell lineage depends on axons for its survival. J Neurocytol 13:961-974.

Dixon RG, Eng LF (1984) Myelin basic protein in the optic nerve of the developing albino rat: an immunoperoxidase study of paraffin embedded tissue. Neurochem Res 9:1387-1397.

Dubois-Dalcq M, Behar T, Hudson L, Lazzarini RA (1986) Emergence of three myelin proteins in oligodendrocytes cultured without neurons. J Cell Biol 102:384-392.

Giulian D, Johnson B, Krebs JF, Tapscott MJ, Honda SA (1991) A growth factor from neuronal cell lines stimulates myelin protein synthesis in mammalian brain. J Neurosci 11:327-336.

Gyllensten L, Malmfors T (1963) Myelinization of the optic nerve and its dependence on visual function - a quantitative investigation in mice. J Embryol Exp Morphol 11:255-266.

Gyllensten L, Malmfors T, Norrlin-Grettve M-L (1966) Developmental and functional alterations in the fiber composition of the optic nerve in visually deprived mice. J Comp Neurol 128:413-418.

Jung HJ, Raine CS, Suzuki K (1978) Schwann cells and peripheral nervous system myelin in the rat retina. Acta Neuropathol (Berl) 44: 245-247.

Kalderon D, Roberts BL, Richardson WD, Smith AE (1984) A short amino acid sequence able to specify nuclear location. Cell 39:499509.

Katsuki K, Sato M, Kimura M, Yokoyama K, Kobayashi K, Nomura $T$ (1988) Conversion of normal behavior to shiverer by myelin basic protein antisense cDN $\Lambda$ in transgenic mice. Science 241:593-595.

Knobler RL, Stempak JG (1973) Serial section analysis of myelin development in the central nervous system of the albino rat: an electron microscopical study of early axonal ensheathment. Prog Brain Res 40:407-423.

Knobler RL, Stempak JG, Laurencin M (1974) Oligodendroglial ensheathment of axons during myelination in the developing rat central nervous system. A serial section electron microscopical study. J Ultrastruct Res 49:34-49.

Kristensson K, Zeller NK, Duboisj-Dalcq ME, Lazzarini RA (1986) Expression of myelin basic protein gene in the developing rat brain as revealed by in situ hybridization. J Histochem Cytochem 34:467473.

Matthews MA, Duncan D (1971) A quantitative study of morphological changes accompanying the initiation and progress of myelin production in the dorsal funiculus of the rat spinal cord. J Comp Neurol 142:1-22.

McCarthy GF, Leblond CP (1988) Radioautographic evidence for slow astrocyte turnover and modest oligodendrocyte production in the corpus callosum of adult mice infused with ${ }^{3} \mathrm{H}$-thymidine. J Comp Neurol 271:589-603.

Meier C, Herschkowitz N, Bischoff A (1974) Morphological and biochemical observations in the jimpy spinal cord. Acta Neuropathol (Berl) 27:349-362.

Miura M, Tamura T, Aoyama A, Mikoshiba K (1989) The promoter elements of the mouse myelin basic protein gene function efficiently in NG108-15 neuronal/glial cells. Gene 75:31-38.

Narang HK, Wisniewski HM (1977) The sequence of myelination in the epiretinal portion of the optic nerve in the rabbit. Neuropathol Appl Neurobiol 3:15-27.

Newman SL, Kitamura K, Roth HJ, Kronquist K, Kerlero de Rosbo N, Crandall BF, Campagnoni AT (1987) Differential expression of the myelin basic protein genes in mouse and human. J Neurochem 48:S27.

Perry VH, Henderson Z, Linden R (1983) Postnatal changes in retinal ganglion cell and optic axon populations in the pigmented rat. J Comp Neurol 219:356-368.

Popko B, Puckett C, Lai E, Shine HD, Readhead C, Takashashi N, Hunt SW, Sidman RL, Hood L (1987) Myelin deficient mice: expression of myelin basic protein and generation of mice with varying levels of myelin. Cell 48:713-721.

Readhead C, Popko B, Takashashi N, Shine HD, Saavedra RA, Sidman RL, Hood L (1987) Expression of a myelin basic protein gene in transgenic shiverer mice: correction of the dysmyelinating phenotype. Cell 48:703-712.

Remahl S, Hildebrand C (1990a) Relation between axons and oligodendroglial cells during initial myelination. I. The glial unit. J Neurocytol 19:313-328.

Remahl S, Hildebrand C (1990b) Relations between axons and oli- 
godendroglial cells during initial myelination. II. The individual axon. J Neurocytol 19:883-898.

Rozeik C, Von Keyserlingk D (1987) The sequence of myelination in the brainstem of the rat monitored by myelin basic protein immunohistochemistry. Dev Brain Res 35:183-190.

Schwab ME, Schnell L (1989) Region-specific appearance of myelin constituents in the developing rat spinal cord. J Neurocytol 18:161169.

Sefton AJ, Lam K (1984) Quantitative and morphological studies on developing optic axons in normal and enucleated albino rats. Exp Brain Res 57:107-117.

Shanker G, Campagnoni AT, Pieringer RA (1987) Investigations on myelinogenesis in vitro: developmental expression of myelin basic protein mRNA and its regulation by thyroid hormone in primary cerebral cell cultures from embryonic mice. J Neurosci Res 17:220224.

Skoff RP, Price DL, Stocks A (1976a) Electron microscopic autoradiographic studies of gliogenesis in rat optic nerve. I. Cell proliferation. J Comp Neurol 169:291-312.

Skoff RP, Price DL, Stocks A (1976b) Electron microscopic autoradiographic studies of gliogenesis in rat optic nerve. II. Time of origin. J Comp Neurol 169:313-334.

Skoff RP, Toland D, Nast E (1980) Pattern of myelination and distribution of neuroglial cells along the developing optic system of the rat and rabbit. J Comp Neurol 191:237-253.

Sternberger NH, Itoyama Y, Kies MW, Webster H (1978) Myelin basic protein demonstrated immunocytochemically in oligodendroglia prior to myelin sheath formation. Proc Natl Acad Sci USA 75: $2521-2524$.

Tennekoon GI, Cohen SR, Price DL, McKhann GM (1977) Myelinogenesis in optic nerve. J Cell Biol 72:604-616.

Trapp BD, Moench T, Pulley M, Barbosa E, Tennekoon G, Griffin J (1987) Spatial segregation of mRNA encoding myelin-specific proteins. Proc Natl Acad Sci USA 84:7773-7777.

Turnley AM, Morahan G, Okano H, Bernard O, Mikoshiba K, Allison J, Bartlett PF, Miller JFAP (1991) Dysmyelination in transgenic mice resulting from expression of class 1 histocompatibility molecules in oligodendrocytes. Nature 353:566-569.

Vaughn JE (1969) An electron microscopic analysis of gliogenesis in rat optic nerves. Z Zellforsch 94:293-324.

Yoshioka T, Feigenbaum L, Jay G (1991) Transgenic mouse model for central nervous system demyelination. Mol Cell Biol 11:54795486.

Zeller NK, Hunkeller MJ, Campagnoni AT, Sprague J, Lazzarini RA (1984) Characterization of mouse myelin basic protein messenger RNAs with a myelin basic protein cDNA clone. Proc Natl Acad Sci USA 81:18-22.

Zeller NK, Behar TN, Dubois-Dalcq ME, Lazzarini RA (1985) The timely expression of myelin basic protein gene in cultured rat brain oligodendrocytes is independent of continuous neuronal influences. J Neurosci 5:2955-2962. 